\title{
FATORES CRÍTICOS DE SUCESSO NA GESTÃO DO CONHECIMENTO: UMA REVISÃO BIBLIOGRÁFICA
}

\author{
FLÁVIA HELENA BARIONI ZANCHETA* \\ IEDA PELAGIO MARTINS DAMIAN*
}

\begin{abstract}
RESUMO
A gestão do conhecimento tem conquistado um espaço maior nas organizações e no meio acadêmico. Aquelas que se dedicaram a implantá-la têm alcançado resultados excelentes em alguns casos, porém insucessos em outros. Para que mais casos de sucesso possam ser alcançados, é de extrema importância identificar os fatores críticos de sucesso para a gestão do conhecimento. Dessa forma, o presente estudo tem como propósito verificar os principais fatores críticos de sucesso da gestão do conhecimento. Para tanto, foi desenvolvido um levantamento bibliográfico de modo que, ao final, foi possível identificar uma diversidade de fatores e, então, construir um quadro com os cinco fatores críticos de sucesso de maior importância na implantação de estratégias de gestão do conhecimento. Verificou-se, ainda, suas principais características e os autores que os citam, e, a partir deste quadro, tecer comentários e considerações que possam contribuir para o aprofundamento do tema junto à Ciência da Informação.
\end{abstract}

PALAVRAS-CHAVE: Gestão do conhecimento, Fatores críticos de sucesso, Contexto organizacional.

\section{CRITICAL FACTORS OF SUCCESS IN KNOWLEDGE MANAGEMENT: A BIBLIOGRAPHIC REVIEW}

\begin{abstract}
Knowledge management has conquered a greater place in organizations and academic circle. Organizations that have dedicated themselves to implementing it have achieved excellent results in some cases, but failures in others. For more successful cases to be achieved,
\end{abstract}

* flavia.zancheta@usp.br: Graduanda do ultimo ano do curso de Biblioteconomia e Ciência da Informação pela Faculdade de Filosofia, Ciências e Letras de Ribeirão Preto (FFCLRP) da Universidade de São Paulo (USP).

** iedapm@usp.br: Docente da Universidade de São Paulo no curso de graduação em Ciência da Informação e Documentação do Departamento de Educação, Comunicação e Informação da Faculdade de Filosofia, Ciências e Letras FFCLRP/USP. Docente do Programa de Pós-graduação em Ciência da Informação na Unesp - Marília - SP. 
identifying the critical success factors for knowledge management is of utmost importance. Thus, the present study aims to identify the main critical success factors of knowledge management. In order to do so, a bibliographic survey was developed so that, in the end, it was possible to identify a diversity of factors and then build a framework with the five critical success factors of greatest importance in the implementation of knowledge management strategies, their main characteristics and the authors that mention them, and, from this table, make comments and considerations that may contribute to the deepening of the topic with the Information Science.

KEY WORDS: Knowledge management, Critical success factors, Organizational context.

\section{INTRODUÇÃO}

Com a publicação do livro "Criação de conhecimento na empresa: Como as Empresas Japonesas Geram a Dinâmica da Inovação", de Nonaka e Takeuchi, em 1997, as discussões a respeito do conhecimento, das formas de gerenciá-lo e dos fatores que trariam sucesso ou insucesso para esse processo aumentaram. Muitos autores, como Nonaka e Takeuchi (1997), Terra (2005), Barros (2010) e Souza, Dias e Nassif (2011) afirmam que a Gestão do Conhecimento (GC) é uma forma estratégica de tornar as organizações mais inovadoras e competitivas e, dessa forma, se manterem no mercado.

Nonaka e Takeuchi (1997, p. 1) explanam que o sucesso das organizações se deve à capacidade e especialização na criação do conhecimento organizacional. Eles entendem por criação do conhecimento organizacional "A capacidade de uma empresa de criar novo conhecimento, difundi-lo na organização como um todo e incorporá-lo a produtos, serviços e sistemas." (Ibidem). Os autores ressaltam, ainda, que a chave para a inovação é a criação do conhecimento organizacional.

Para Terra (2005, p. 2), a GC se ocupa

dos processos gerenciais e infraestrutura física e digital que facilitam, favorecem e estimulam os processos de criação, compartilhamento e uso de conhecimentos individuais e coletivos.

O autor destaca, ainda, que gerenciar conhecimento é bem diferente de gerenciar dados ou informação; o conhecimento só existe na cabeça das pessoas, é um recurso invisível, intangível e de difícil imitação, porém é um recurso reutilizável, que, quanto mais usado e emitido, mais valor tem, e seu efeito de depreciação funciona 
de maneira oposta, em que a depreciação se acelera sem a aplicação do mesmo, "se não se está adquirindo conhecimento, é bem provável que se esteja perdendo." (Terra, 2005, p. 33).

Desta forma, fica clara a importância do recurso "conhecimento". Isso porque, ele é o princípio básico para que haja gestão do conhecimento, é crucial que se encontre maneiras de obtê-lo e disseminá-lo por toda a organização. Para que isso ocorra, é necessário implantar uma cultura de confiança, que valorize as pessoas e seus conhecimentos, além de ações de troca.

Com o objetivo de otimizar a gestão do conhecimento, deve-se, também, analisar os elementos que, se bem administrados, seriam capazes de trazer benefícios para esse tipo de gestão. Além disso, estes elementos, comumente chamados de fatores críticos de sucesso (FCS), tornam-se atividades de extrema relevância.

Rockart (1979) apud Wong (2005, p. 262) diz que os FCS podem ser definidos como "áreas em que os resultados, se forem satisfatórios, garantirão um desempenho competitivo bem-sucedido para a organização". Essas áreas podem ser vistas como as atividades e práticas que precisam ser abordadas para garantir sucesso na implantação da GC. As organizações devem, portanto, estar conscientes dos fatores capazes de influenciar as iniciativas da mesma. (WONG, 2005).

Assim, este estudo se propõe a realizar um levantamento bibliográfico sobre a "Gestão do conhecimento e fatores críticos de sucesso para as iniciativas de GC". E, a partir deste, analisar os FCS listados para, então, construir um quadro explicativo que demonstre os principais fatores para a GC, suas características centrais e os autores que os abordaram.

\section{GESTÃO DO CONHECIMENTO: CONTEXTUALIZAÇÃO}

Com o objetivo de melhor compreender o que de fato é o conhecimento, se faz necessário diferi-lo de dado e informação.

CONHECIMENTO não é dado nem informação, embora esteja relacionado com ambos e as diferenças entre esses termos sejam normalmente uma questão de grau. [...] Por mais primário que possa soar, é importante frisar que dado, informação e conhecimento não são sinônimos. O sucesso ou o fracasso organizacional muitas vezes pode depender de se saber de qual deles precisamos, com qual deles contamos e o que podemos ou não fazer com cada um deles. (DAVENPORT \& PRUSAK, 1998, p. 1) 
Dado, para Davenport e Prusak (1998, p. 02), é o:

conjunto de fatores distintos e objetivos, relativos a eventos. Num contexto organizacional, dados são utilitariamente descritos como registros estruturados de transações.

Estes afirmam, ainda, que apesar dos dados nada falarem a respeito da "própria importância ou irrelevância. [...] são importantes para as organizações - em grande medida, certamente, porque são matéria-prima essencial para a criação da informação". (DAVENPORT \& PRUSAK, 1998, p. 3, grifo nosso).

Informações, de acordo com Drucker (1999, p. 32), "São dados interpretados, dotados de relevância e propósito". Desse modo, a informação é vista como um dado que faz a diferença, que dá forma e muda a perspectiva e o pensamento do receptor. Ela pode ser audível ou visível, ou aparecer na forma de documento. (DAVENPORT \& PRUSAK, 1998).

O conhecimento:

é uma mistura fluida de experiência condensada, valores, informação contextual e insight experimentado, a qual proporciona uma estrutura para a avaliação e incorporação de novas experiências e informações. Ele tem origem e é aplicado na mente dos conhecedores. Nas organizações, ele costuma estar embutido não só em documentos ou repositórios, mas também em rotinas, processos, práticas e normas organizacionais. (DAVENPORT \& PRUSAK, 1998, p. 6)

O conhecimento se encontra no mundo dos conceitos, enquanto que a informação no dos registros. Brascher e Café (2008), para explicar os conceitos de informação e conhecimento, sistematizam algumas características citadas por Fogh (1979):

1) Conhecimento é o resultado da cognição (processo de reflexão das leis e das propriedades de objetos e fenômenos da realidade objetiva na consciência humana); 2) Conhecimento é o conteúdo ideal da consciência humana; 3) Informação é uma forma material da existência do conhecimento; 4) Informação é um item definitivo do conhecimento expresso por meio da linguagem natural ou outros sistemas de signos percebidos pelos órgãos e sentidos; 5) Informação existe e exerce sua função social por meio de um suporte físico; 6) Informação existe objetivamente fora da consciência individual e independente dela, desde o momento de sua origem. (FOGH, 1979 apud BRASCHER \& CAFÉ, 2008, p. 4). 
Nonaka e Takeuchi, (1997, p. 63) diferenciam os dois conceitos, afirmando que:

A informação é um meio ou material necessário para extrair e construir o conhecimento. Afeta o conhecimento acrescentando-lhe algo ou o reestruturando. (MACHLUP, 1983, apud NONAKA \& TAKEUCHI, 1997, p. 63). O conhecimento adverso a informação, refere-se a crenças, compromissos e ação; é função de uma atitude, perspectiva ou intenção específica. Assim como a informação, o conhecimento diz respeito ao significado por ser específico ao contexto e relacional.

Da mesma forma que informação e conhecimento são diferentes, Gestão do Conhecimento (GC) e Gestão da Informação (GI) também são. A respeito da GC e da GI, Valentim (2004, p. web), ressalta que:

A gestão da informação é um conjunto de estratégias que visa identificar as necessidades informacionais, mapear os fluxos formais de informação nos diferentes ambientes da organização, assim como sua coleta, filtragem, análise, organização, armazenagem e disseminação, objetivando apoiar o desenvolvimento das atividades cotidianas e a tomada de decisão no ambiente corporativo. A gestão do conhecimento é um conjunto de estratégias para criar, adquirir, compartilhar e utilizar ativos de conhecimento, bem como estabelecer fluxos que garantam a informação necessária no tempo e formato adequados, a fim de auxiliar na geração de ideias, solução de problemas e tomada de decisão.

Como, muitas vezes, GC é usada no sentido de Gl e vice-versa, é necessário esclarecer o papel de cada uma dessas gestões e seus focos. Seguindo o raciocínio de Valentim (2004), a gestão da informação se apoia nos fluxos formais (conhecimento explícito), enquanto a gestão do conhecimento, nos fluxos informais (conhecimento tácito).

O conhecimento explícito trabalha com o que está registrado, visto que se encontra formalizado em meios concretos, como banco de dados, documentos e outros, constituindo-se no que é tangível. É, portanto de fácil transmissão. Por outro lado, o conhecimento tácito é pessoal, como: conversas de corredor, reuniões, experiência na prática; não se encontra formalizado em meios concretos, e se constitui no que é intangível e, então, é de difícil comunicação. (NONAKA \& TAKEUCHI, 1997; VALENTIM, 2004)

$\mathrm{Na}$ literatura, a gestão do conhecimento é explicada de diversas formas. Jarrar (2002, p. 322, tradução nossa) explana que: 
[...] a gestão do conhecimento é o processo de gerenciamento continuo que visa atender às necessidades emergentes, identificar $e$ explorar os recursos de conhecimento existente para desenvolver novas oportunidades.

Terra (2005, p. 85, grifo do autor) menciona que a GC está totalmente ligada:

à capacidade das empresas em utilizarem e combinarem as várias fontes e tipos de conhecimento organizacional para desenvolverem competências especificas e capacidade inovadora, que se traduzem, permanentemente, em novos produtos, processos, sistemas gerenciais e liderança de mercado.

Para Hoffmamm (2016, p. 9), a GC, tanto em instituições públicas quanto privadas, foca no "conhecimento organizacional e estratégico que faz parte da administração organizacional sistemática, incluindo pessoas, processos, produtos e serviços". Estes elementos são fundamentais na criação do conhecimento, pois, quando organizados da forma correta, podem gerar inovação. A autora define que a GC tem como propósito:

gerenciar o conhecimento das pessoas e organizações, através do acesso, coleta, tratamento e análise das informações e seu compartilhamento em ambientes ou espaços físicos ou virtuais que oferecem um contexto apropriado para a geração e uso do conhecimento, onde as pessoas se reúnem, fazem reflexões críticas, compartilham experiências e melhores práticas, em que efetivamente se comunicam, possibilitando a interação entre o conhecimento tácito e o conhecimento explícito.

Contudo, Nonaka \& Takeuchi (1997, p. 65) afirmam que a organização não é capaz de criar conhecimento sem indivíduos, pois o conhecimento só é criado por indivíduos. Assim sendo, Teixeira Filho (2000, p. 22) diz que "as atividades de criação de conhecimento têm lugar com os seres humanos e entre eles".

Nonaka e Takeuchi (1997, p.67) ressaltam que, apesar de diferentes, o conhecimento tácito e o explicito:

não são entidades totalmente separadas, e sim mutuamente complementares. Interagem um com o outro e realizam trocas nas atividades criativas dos seres humanos.

Os autores chamam essa interação de "conversão do conhecimento" e postulam existir quatro maneiras de efetuá-la entre os tipos de conhecimento: 
(1) Socialização: faz a conversão do conhecimento tácito em conhecimento tácito, onde a criação deste conhecimento se dá pelo processo de compartilhamento de experiências.

(2) Externalização: converte o conhecimento tácito em explicito, por meio da utilização de analogias, metáforas, conceitos, hipóteses ou modelos. A chave para a construção do conhecimento é a externalização, motivada pelo diálogo ou pela reflexão coletiva.

(3) Combinação: transforma o conhecimento explícito em explícito, por meio da sistematização de conceitos que envolvem diversas combinações. A troca e a combinação desse tipo de conhecimento ocorrem via reuniões, conversas telefônicas, redes de comunicação, entre outros.

(4) Internalização: envolve a conversão do conhecimento explícito em conhecimento tácito, e está totalmente relacionada com o saber na prática.

Choo (2006, p. 36-37) acrescenta que a construção do conhecimento se dá

[...] quando se reconhece o relacionamento sinérgico entre o conhecimento tácito e o explícito dentro de uma organização são elaborados processos sociais capazes de criar novos conhecimentos por meio da conversão do conhecimento tácito em conhecimento explícito.

A interação mencionada é conhecida como espiral do conhecimento (figura 1), ou espiral SECl, construída pelas mudanças entre os diferentes modos de conversão do conhecimento:

Figura 1 - Espiral do conhecimento

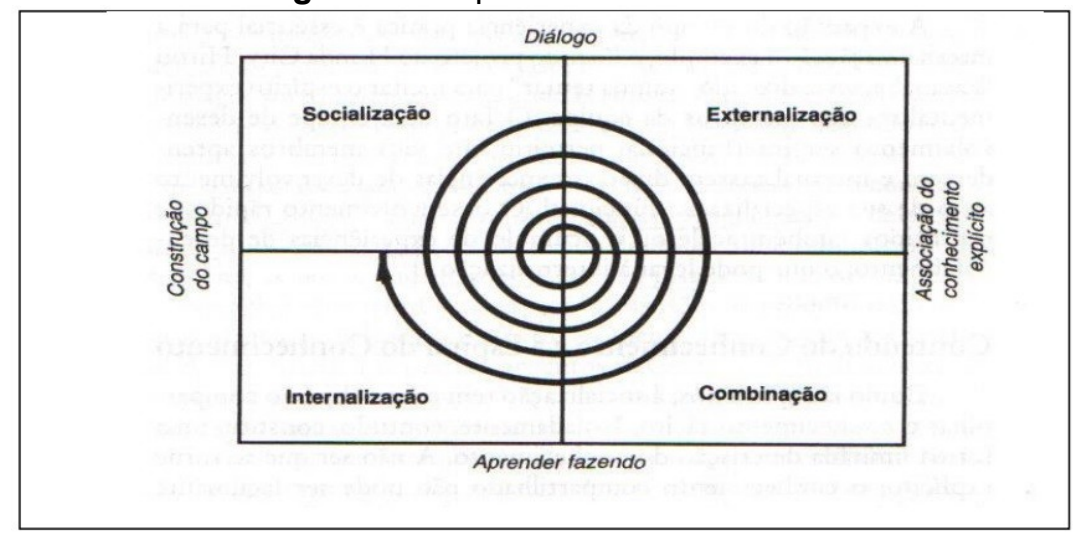

FONTE: Nonaka e Takeuchi (1997, p. 80) 
Terra (2005, p. 82) concorda com os autores quando diz que essa espiral é:

baseada no comprometimento pessoal e em vários processos de conversão entre o conhecimento implícito e o explicito, envolvendo desde o indivíduo até o grupo, a organização e o ambiente.

Contudo, alguns autores acreditam que a GC deveria se chamar "gestão da mente humana", já que o conhecimento reside dentro dela, e este estaria no mundo dos conceitos. Devido a esse pensamento, uma parcela não acredita que exista Gestão do Conhecimento, como é o caso de Tom Wilson (2006):

[...] não existe gestão do conhecimento, uma vez que o conhecimento reside nas pessoas. O que pode ser feito é tentar gerenciar a organização de modo a assegurar que o desenvolvimento da aprendizagem e das habilidades seja encorajado e que a cultura organizacional promova o compartilhamento da informação (WILSON, 2006, p. 54).

Em relação aos benefícios da GC, Barros (2010, p. 35) afirma que "a gestão do conhecimento é uma ferramenta estratégica importante, uma vez que o conhecimento é o aprendizado compartilhado e a força de trabalho da organização". Os indivíduos se encontram em constante aprendizagem e constroem seu conhecimento por meio da experiência prática e da relação com o outro.

Para Brito (2008, p. 137), a GC:

teria como principal desafio a aquisição e a transferência do conhecimento pessoal do trabalhador (tácito) e do conhecimento declarativo (explícito) num processo de transformação interativa e em espiral.

A transformação interativa a qual a autora se refere é o ciclo de conversão do conhecimento em quatro modos (socialização, externalização, combinação e internalização). Esses modos, em interação, fazem surgir a espiral do conhecimento ou espiral SECI (processos discutidos anteriormente).

De acordo com Floriano (2009), as organizações podem utilizar diversos métodos para estimular seus colaboradores a compartilhar conhecimento. Porém, independentemente do estímulo utilizado, se torna fundamental que os indivíduos se sintam plenamente bem em realizar tal atividade, e notem os benefícios do compartilhamento do conhecimento como algo totalmente positivo, tanto para a organização como para sua trajetória profissional. 
Barros (2010) afirma que o compartilhamento do conhecimento é de difícil implantação por depender mais da cultura organizacional do que de ferramentas tecnológicas. Motivar as pessoas a compartilhar conhecimento envolve tempo, dinheiro, e, acima de tudo, a superação de diversos obstáculos. Contudo, os benefícios de tal processo são inegáveis; entre estes se destaca: a capacidade das organizações se tornarem mais competitivas; a maior valorização da força de trabalho pela organização; a motivação dos funcionários e, por consequência, um maior rendimento na produção; o estimulo à aprendizagem; a maior capacidade de inovação; a não exigência de grandes gastos; a utilização de recursos já existentes, ou seja, o conhecimento dos membros do grupo organizacional; as soluções mais rápidas ou imediatas e as melhorias notadas pelos clientes.

Os benefícios advindos da GC podem variar de uma organização para outra. Desse modo, quanto maior forem as evidências dos benefícios provenientes da GC, mais importante e fundamental a mesma será para a organização.

A GC é utilizada em qualquer organização que pretende inovar e criar vantagem competitiva. Silva (2004) ressalta que a implantação coordenada da GC possibilita a criação de vantagem competitiva sustentável, de difícil imitação por estar enraizada nas pessoas que compõem o grupo empresarial e não os recursos físicos, que podem ser facilmente imitáveis pelos concorrentes.

Arora (2002) afirma que a gestão do conhecimento tem trazido benefícios surpreendentes a algumas organizações, porém insucesso a outras. Para a autora, as empresas que seguem a GC com objetivos e abordagens claros e bem definidos tendem a obter maior sucesso.

Para que a GC seja bem-sucedida, é preciso que a criação, o armazenamento, a recuperação, a transferência e a aplicação do conhecimento sejam funções executadas com qualidade. No entanto, outros fatores podem influenciar no sucesso da GC. (JENNEX e OLFMAN, 2004). Dessa forma, é de extrema importância para as organizações que desejam ser bem-sucedidas compreender quais são os fatores críticos de sucesso.

\section{FATORES CRÍTICOS DE SUCESSO: CONTEXTUALIZAÇÃO}

Para Damodaran e Olphert (2000), a identificação de FCS serve de base para um processo de gerenciamento de mudanças que inclui o desenvolvimento da cultura de compartilhamento de conhecimento necessário para uma efetiva GC. 
Os FCS são, segundo Gonçalves, Colauto e Beuren (2004 p. 6)

entendidos como elementos determinantes para 0 melhor desempenho, pois, se a organização os identificar e conseguir incorporá-los ao planejamento estratégico, aos sistemas de informação, estes passam a complementar as atividades de análise competitiva. Considera-se que uma das contribuições dos fatores críticos de sucesso é subsidiar as informações de caráter estratégico, sendo que estas informações ganham importância quando alinhadas aos objetivos institucionais.

Não existe um consenso acerca dos fatores críticos de sucesso. Alguns autores utilizam o termo fatores-chave, pelo fato destes serem pontos fundamentais para as organizações. Quando perfeitamente executados, colaboram para o sucesso das organizações; do contrário, podem levar ao fracasso.

Tarapanoff (2001, p. 311) afirma que estes fatores representam:

os meios que garantem a realização dos objetivos da organização, ou seja, fatores que, pela sua natureza, podem comprometer todo o sucesso de um plano ou de uma estratégia, devendo ser considerados como "críticos" e merecer atenção especial por parte da administração.

Hasanali (2002) explana que o sucesso da GC depende de fatores diversos, estando alguns ao nosso controle, enquanto outros não. Segundo Wong (2005), os fatores internos são controláveis pelas organizações, enquanto os fatores externos, como, por exemplo, as influências ambientais estariam fora de seu controle.

Para Hasanali (2002), os FCS podem ser divididos em cinco categorias, conforme apresentado no quadro a seguir (quadro 1):

Quadro 1 - Fatores críticos de sucesso segundo Hasanali (2002) 1. liderança: desempenha papel fundamental para a garantia de sucesso em qualquer iniciativa em uma organização;

2. cultura: faz se necessário destruir algumas das barreiras existentes ao compartilhamento do conhecimento e dar as pessoas as ferramentas e o ambiente de que precisam para se criar uma cultura de compartilhamento;

3. estrutura, papéis e responsabilidades: embora existam várias maneiras pelas quais as organizações estruturam a governança de suas iniciativas de GC, se encontrou elementos comuns entre as organizações de melhores práticas: um comitê de direção que promove conceitos e fornece orientação, direção e suporte; um grupo central de suporte a GC que oferece o apoio inicial para projetos ou iniciativas; e administradores/proprietário que são responsáveis pelo compartilhamento de conhecimento e aquisição dentro das unidades de negócios; 
4. infraestrutura de tecnologia da informação: sem uma sólida infraestrutura de TI, uma organização não consegue permitir que seus funcionários compartilhem informações em grande escala. Uma iniciativa de GC não se restringe a aplicação de um software; ter uma plataforma para comunicar e compartilhar informações é apenas parte de uma iniciativa;

5. medição: devido à incapacidade de isolar por completo os resultados do compartilhamento de conhecimento, torna se fundamental rastrear as correlações ao longo do tempo.

FONTE: Elaborado pelo autor.

Damodaran e Olphert (2000) destacam os seguintes FCS:

- Direção por aqueles que estão no topo da organização indicando a importância da GC para a mesma;

- Implementação de caminho rápido - para evitar descréditos e enfraquecer resistências;

- Integração com outras iniciativas da empresa - como forma de aproveitar sinergias e, possivelmente, economizar recursos;

- Institucionalização de práticas normais de trabalho - para criar cultura e práticas apropriadas;

- Agregação de valor para indivíduos e equipes - com o objetivo de favorecer o engajamento espontâneo;

- Relacionamento claro com as necessidades comerciais específicas - de forma a evitar possíveis desalinhamentos estratégicos ou perda de foco;

- Facilitação e rapidez de uso - favorecendo uma maior adesão a utilização;

- Comunicação, treinamento e apoio adequados - também colaborando para uma maior adesão e de maneira mais acelerada;

- Banco de dados recheado com massa crítica - que favorece a credibilidade do sistema;

- Construção de uma cultura de confiança - que se torna requisito básico para que aconteça o compartilhamento de conhecimento.

Goh (2002) afirma que, para obter sucesso na transferência de conhecimento, alguns fatores devem ser levados em consideração. Sendo estes:

- Liderança: os líderes têm um importante papel na construção de condições necessárias para facilitar a transferência de conhecimento. Eles devem demonstrar 
vontade em compartilhar informação e conhecimento e despertar nos outros essa mesma aspiração.

- Solução de problemas/mudanças de comportamentos: uma forma de conduzir a transferência de conhecimento é o incentivo a uma cultura de resolução de problemas. Os funcionários devem ser encorajados a adotar uma atividade contínua de melhoramento e aprendizagem, focando em valores importantes para a organização, como o atendimento ao cliente, o custo-benefício ou a qualidade do produto.

- Estruturas de apoio: se faz necessária uma infraestrutura adequada para reforçar e apoiar o compartilhamento do conhecimento. Tais estruturas podem ser de tecnologia, treinamento e desenvolvimento de habilidades, recompensas e design organizacional.

- Capacidade de absorção e retenção: a organização deve certificar-se de que ambas as partes no processo de transferência de conhecimento possuam a mesma base de conhecimento, para que possam aprender e se entender.

- Tipos de conhecimento: a organização necessita entender qual o tipo de conhecimento a ser transferido, se é tácito ou explicito. Determinar como cada tipo de conhecimento pode ser codificado e transferido é um desafio.

Terra (2005) cita os FCS como normas, práticas e processos capazes de estimular ou inibir a geração, captação, difusão e armazenamento de conhecimento pelas empresas. Ele os divide conforme as sete dimensões expostas no quadro a seguir (quadro 2).

Quadro 2 - Os 7 FCS apontados por Terra (2005)

$1^{\circ}$ Fatores estratégicos e 0 papel da alta administração: a alta administração deve definir os campos de conhecimento, as metas desafiadoras e incentivar o enfrentamento de riscos;

$\mathbf{2}^{\circ}$ Cultura e valores organizacionais: a organização deve desenvolver uma cultura organizacional voltada à inovação, experimentação, e ao aprendizado continuo. Os resultados não precisam aparecer a curto prazo, e as pessoas não precisam estar focadas apenas em sua área de atuação;

$3^{\circ}$ Novas estruturas organizacionais e práticas de organização do trabalho: devem ser adotadas para superar as fronteiras à inovação, aprendizado e à geração de novos conhecimentos, que são impostos pelas estruturas de tradição. 
$4^{\circ}$ Administração de recursos humanos (RH): devem nortear as políticas e práticas de gestão de $\mathrm{RH}$, tendo em vista melhorar a capacidade das organizações de aproximar e de manter profissionais hábeis, com comportamentos e competências que acrescentem aos estoques e aos fluxos de conhecimento das mesmas.

$5^{\circ}$ Sistemas de informação: processo de geração, difusão e armazenamento do conhecimento nas empresas. As tecnologias podem ser aplicadas em mecanismos que facilitem o compartilhamento do conhecimento entre os empregados, e que torne a gestão do conhecimento algo explicito.

$6^{\circ}$ Mensuração de resultados: deve se destacar os benefícios de medir os resultados.

$7^{\circ}$ Aprendizado com o ambiente externo: as empresas aprendem com o ambiente, em principal por meio de alianças estratégicas.

FONTE: Elaborado pelo autor.

Skyrne e Amidon (1997) também destacam sete fatores:

(1) Forte ligação com um imperativo de negócios - apesar de não ser facilmente calculado o valor do conhecimento, fica claro que os programas e processos de conhecimento são vitais no apoio aos objetivos da organização;

(2) Uma visão convincente e da arquitetura - "Geralmente, algum quadro forneceu o "gancho" em torno do qual construiu-se uma linguagem e impulso para a mudança." (SKYRNE E AMIDON,1997, p. 33, tradução nossa)

(3) Liderança do conhecimento - a alta administração é geralmente a campeã no apoio ao conhecimento.

(4) Uma cultura de criação e compartilhamento de conhecimento.

(5) Aprendizado contínuo - aprender em todos os níveis, e com os erros.

(6) Uma infraestrutura tecnológica bem desenvolvida.

(7) Processos sistemáticos de conhecimento organizacional "Estrutura e processos para identificar, capturar e difundir conhecimentos importantes de forma estruturada" (SKYRNE E AMIDON, 1997, p. 33, tradução nossa)

De acordo com Wong (2005), onze fatores devem ser considerados críticos para o sucesso da implantação da GC nos contextos organizacionais. Estes estão divididos conforme o quadro abaixo (quadro 3). 
Quadro 3 - Os 11 fatores críticos de sucesso para Wong (2005)

Gestão de liderança e suporte: os líderes atuam como modelos que exemplificam o comportamento desejado, mostrando vontade em compartilhar e aprender continuamente;

Cultura: a cultura organizacional define as "principais crenças, valores, normas e costumes sociais que governam o modo como os indivíduos agem e se comportam organizacionalmente." (WONG, 2005 p. 267, tradução nossa). Para o autor, uma cultura que apoia a GC é aquela que reconhece o valor do conhecimento e oferece condições para a criação, compartilhamento e aplicação de tal recurso;

Tecnologia da informação: permite a busca, acesso e recuperação a informação de maneira rápida, podendo suportar a colaboração e comunicação entre os integrantes da organização;

Estratégia e propósito: "Um dos meios para impulsionar o sucesso da GC é ter uma estratégia clara e bem planejada onde os objetivos devem ser compreendidos por todos os envolvidos." (LIEBOWITZ, 1999 apud WONG, 2005 p. 270);

Medição: atua como um sistema de coleta de dados capaz de oferecer informações sobre uma situação ou atividade especifica; se faz necessária para demonstrar o mérito e o valor das iniciativas de GC;

Infraestrutura organizacional: criação de uma infraestrutura organizacional apropriada, como por exemplo estabelecimento de um grupo que desempenhe um conjunto de papeis relacionados ao conhecimento;

Processos e atividade: "Um processo de gestão do conhecimento refere-se a algo que pode ser feito com o conhecimento na organização." (JOHANNSEN, 2000 apud WONG, 2005, p. 271);

Ajuda motivacional: diz respeito ao incentivo aos funcionários. Colabora e reforça os comportamentos e culturas positivas necessários a uma efetiva gestão;

Recursos: para que a GC tenha sucesso, dispor de recursos tanto financeiros, quanto tecnológicos, humanos e materiais é crucial;

Treinamento e educação: um treinamento básico, porém adequado, deve ser oferecido aos funcionários, para que estes saibam promover a criatividade, inovação, e compartilhamento de conhecimento e saibam também como utilizar as ferramentas tecnológicas para gerenciá-lo. $\mathrm{E}$, acima de tudo, para que compreendam os conceitos da gestão do conhecimento;

Gestão de recursos humanos: como o conhecimento é uma criação humana, recrutar funcionários com habilidades e conhecimentos desejados é fundamental, já que, por meio desse processo, as competências e o conhecimento são carregados a organização.

FONTE: Elaborado pelo autor 
Holsapple e Joshi (2000) propuseram a existência de três instâncias de influências: gestão, recursos, e ambiente, cada uma possuindo fatores singulares.

A gestão é caracterizada por: (1) Coordenação, que envolve o planejamento e estruturação, a determinação das atividades, os participantes e os recursos adequados de conhecimentos a serem operados, a obtenção de habilidades para a execução de atividades variadas, o arranjo das mesmas no tempo e etc.; (2) Controle, com o objetivo de garantir que os recursos e processadores de conhecimento estejam seguros contra perda, obsolescência, exposição não autorizada, entre outros; e que estes estejam disponíveis em quantidade de qualidade suficientes; (3) Medição, abarca a avaliação de recursos e processos de conhecimento, servindo de base para a avaliação da liderança, da execução de atividades do conhecimento, e os impactos da GC sobre o desempenho final de uma organização; e (4) Liderança, que alinhada "com o propósito e a estratégia da organização, estabelece condições favoráveis para uma GC frutífera." (HOLSAPPLE E JOSHI, 2000, p. 241).

Os recursos são classificados em: (1) Recursos de conhecimento, que representam a matéria-prima para as atividades de conhecimento, e que influenciam a GC, a aprendizagem e a inovação; (2) Recursos humanos, que dizem respeito às habilidades que as pessoas que compõem o grupo organizacional possuem e que facilitam a GC e a realização de atividades de conhecimento; (3) Recursos financeiros, que limitam o que pode ser gasto em atividades de conhecimento. "Aumentar os recursos financeiros disponíveis para uma atividade de conhecimento [...] talvez afetem a eficiência dessa atividade ou a qualidade de seus resultados (positivamente ou negativamente)." (HOLSAPPLE E JOSHI, 2000, p. 241, tradução nossa); (4) Recursos materiais, que compreendem as habilidades que os recursos materiais (computador) dispõem e que facilitam a GC e a realização de atividades de conhecimento.

$E$, por fim, as influências ambientais (ambiente externo) que contam com fatores atrelados à concorrência, à moda, aos mercados, à tecnologia, à pressão do tempo e às mudanças no clima GEPSE (governamental, econômico, político, social e educacional).

Davenport et al (1998) identificam oito principais contribuintes para a eficácia da gestão do conhecimento, quais sejam: link para o desempenho econômico ou valor industrial; infraestrutura técnica e organizacional; estruturas de conhecimento padrão e flexível; cultura 
de conhecimento; claridade de propósito e linguagem; diferentes práticas motivacionais; vários canais de transferência de conhecimento; e apreciação e apoio da alta gerência.

\section{METODOLOGIA}

Para a construção do presente estudo foi realizado um levantamento bibliográfico. O levantamento, chamado também de revisão de literatura ou revisão bibliográfica, está de acordo com a Biblioteca Dante Moreira de Oliveira (2013). Todo o envolvimento em atividades de busca, análise e descrição do conjunto de conteúdos que servirá de base para a pesquisa, a fim de encontrar resposta a uma pergunta em específico. Sua busca aborda todo o material relevante que foi escrito a respeito da temática abordada, como: livros, artigos de periódicos, artigos de jornais, registros históricos, relatórios governamentais, teses e dissertações, entre outros meios de busca. (Ibidem)

Galvão (2010, p. 1) explana que "realizar um levantamento bibliográfico é se potencializar intelectualmente com o conhecimento coletivo, para ir além". É destacável, ainda, que a autora afirma que o "levantamento bibliográfico clama por um planejamento, sendo primordial explicitar-se em linguagem verbal escrita qual é a temática que será abordada na pesquisa científica", onde a elaboração de tal levantamento deve estar integralmente relacionada ao tema em específico. (GALVÃO, 2010, p. 2)

Buscando seguir esses conceitos, adotou-se como caminho metodológico a busca de matérias que tivessem vínculo com o tema em questão. Essas buscas foram realizadas em bases de dados nacionais e internacionais e em livros. Para a pesquisa em bases de dados internacionais, os seguintes descritores foram usados: "Knowledge management" e "critical success factors", enquanto que, para as bases nacionais: "Gestão do conhecimento" e "fatores críticos de sucesso". Não houve limitação em relação ao tipo de documento, nem quanto à localização do descritor pesquisado.

A contextualização foi realizada por meio de buscas em bases de dados, tanto nacionais quanto internacionais, com livros disponíveis na biblioteca central do acervo USP, e em outros. Já o levantamento bibliográfico dos FCS, na GC, foi obtido em bases de dados internacionais, como a SCOPUS, e em livros da biblioteca central do acervo USP. Tudo isso foi realizado com o objetivo de responder a perguntas como: O que é gestão do conhecimento? Quais seus benefícios e dificuldades? Onde é aplicada? O que é 
fator crítico de sucesso? Tudo isso para, no final, responder à principal questão que é: "Quais são os principais fatores críticos de sucesso para a gestão do conhecimento."

\section{ANÁLISE DE DADOS}

Com base no levantamento bibliográfico realizado, o quadro quatro foi desenvolvido com o intuito de identificar os cinco fatores críticos de sucesso que mais foram citados, bem como a identificação dos autores.

Quadro 4 - Os 5 fatores críticos de sucesso mais relevantes na implementação da gestão do conhecimento.

\begin{tabular}{|c|c|c|c|}
\hline FATORES & VARIÁVEIS & $\begin{array}{c}\text { PRINCIPAIS } \\
\text { CARACTERÍSTICAS }\end{array}$ & AUTORES \\
\hline Liderança & $\begin{array}{l}\text { - Direção pelo topo } \\
\text { da organização; } \\
\text { - Papel da alta } \\
\text { administração; } \\
\text { - Liderança do } \\
\text { conhecimento; } \\
\text { - Gestão de } \\
\text { liderança e suporte; } \\
\text { - Apoio da } \\
\text { alta gerência. }\end{array}$ & $\begin{array}{l}\text { - Definição de } \\
\text { metas, objetivos e } \\
\text { resultados esperados; } \\
\text { - Suporte; } \\
\text { - Disseminação da } \\
\text { importância da GC aos } \\
\text { funcionários; } \\
\text { - Incentivo ao } \\
\text { enfrentamento de riscos } \\
\text { e ao compartilhamento } \\
\text { do conhecimento; } \\
\text { - Modelo de } \\
\text { comportamento } \\
\text { desejado. }\end{array}$ & $\begin{array}{l}\text { Terra (2005); } \\
\text { Wong (2005); } \\
\text { Hasanali (2002); } \\
\text { Goh (2002); } \\
\text { Damodaran e } \\
\text { Olphert (2000); } \\
\text { Holsapple and } \\
\text { Joshi (2000); } \\
\text { Davenport et al } \\
\text { (1998) } \\
\text { Skyrme e Amidon } \\
\text { (1997). }\end{array}$ \\
\hline $\begin{array}{l}\text { Tecnologia da } \\
\text { informação (TI) }\end{array}$ & $\begin{array}{l}\text { - Sistemas de } \\
\text { informação; } \\
\text { - Infraestrutura de } \\
\text { tecnologia da } \\
\text { informação; } \\
\text { - Infraestrutura } \\
\text { tecnológica bem } \\
\text { desenvolvida; } \\
\text { - Estruturas } \\
\text { de apoio; } \\
\text { - Banco de dados } \\
\text { recheado com } \\
\text { massa crítica. }\end{array}$ & $\begin{array}{l}\text { - Mecanismo que visa } \\
\text { facilitar o } \\
\text { compartilhamento do } \\
\text { conhecimento; } \\
\text { - Estruturas tecnológicas } \\
\text { que, se bem } \\
\text { estruturadas, } \\
\text { (adequadas) favorecem } \\
\text { o processo de geração, } \\
\text { difusão e } \\
\text { armazenamento; } \\
\text { - Permite o } \\
\text { compartilhamento de } \\
\text { informações em } \\
\text { grande escala. }\end{array}$ & $\begin{array}{l}\text { Terra (2005); } \\
\text { Wong (2005); } \\
\text { Hasanali (2002); } \\
\text { Goh (2002); } \\
\text { Damodaran e } \\
\text { Olphert (2000); } \\
\text { Davenport et al } \\
\text { (1998) } \\
\text { Skyrme e Amidon } \\
\text { (1997). }\end{array}$ \\
\hline
\end{tabular}


Continuação

\begin{tabular}{|c|c|c|c|}
\hline FATORES & VARIÁVEIS & $\begin{array}{c}\text { PRINCIPAIS } \\
\text { CARACTERÍSTICAS }\end{array}$ & AUTORES \\
\hline $\begin{array}{c}\text { Cultura } \\
\text { organizacional }\end{array}$ & $\begin{array}{l}\text { - Cultura; } \\
\text { - Construção de } \\
\text { cultura de } \\
\text { confiança; } \\
\text { - Cultura de } \\
\text { resolução de } \\
\text { problemas/solução } \\
\text { de problemas; } \\
\text { - Cultura e valores } \\
\text { organizacionais; } \\
\text { - Cultura de criação } \\
\text { e compartilhamento } \\
\text { de conhecimento; } \\
\text { - Cultura de } \\
\text { conhecimento. }\end{array}$ & $\begin{array}{l}\text { - Criação de ambiente } \\
\text { propício para o } \\
\text { compartilhamento do } \\
\text { conhecimento e clima } \\
\text { organizacional positivo; } \\
\text { - Desenvolvimento de } \\
\text { uma cultura voltada a } \\
\text { inovação, } \\
\text { experimentação e } \\
\text { aprendizado continuo; } \\
\text { - Encorajamento para a } \\
\text { criação, } \\
\text { compartilhamento e } \\
\text { aplicação do } \\
\text { conhecimento. }\end{array}$ & $\begin{array}{l}\text { Terra (2005); } \\
\text { Wong (2005); } \\
\text { Hasanali (2002); } \\
\text { Goh (2002); } \\
\text { Damodaran e } \\
\text { Olphert (2000); } \\
\text { Davenport et al } \\
\text { (1998) } \\
\text { Skyrme e } \\
\text { Amidon (1997). }\end{array}$ \\
\hline $\begin{array}{l}\text { Infraestrutura } \\
\text { organizacional }\end{array}$ & $\begin{array}{l}\text { - Estrutura, papeis e } \\
\text { responsabilidades; } \\
\text { - Estruturas de } \\
\text { apoio; } \\
\text { - Novas estruturas } \\
\text { organizacionais } \\
\text { e práticas } \\
\text { de organização } \\
\text { do trabalho. }\end{array}$ & $\begin{array}{l}\text { - Estabelecimento de } \\
\text { papéis e equipes para } \\
\text { realização de tarefas } \\
\text { relacionadas ao } \\
\text { conhecimento; } \\
\text { - Planejamento. }\end{array}$ & $\begin{array}{l}\text { Terra (2005); } \\
\text { Wong (2005); } \\
\text { Hasanali (2002); } \\
\text { Goh (2002); } \\
\text { Davenport et al } \\
\text { (1998). }\end{array}$ \\
\hline Medição & $\begin{array}{l}\text { - Mensuração de } \\
\text { resultados. }\end{array}$ & $\begin{array}{l}\text { - Demonstrar se a GC } \\
\text { está sendo efetiva; } \\
\text { - Oferecer informações } \\
\text { sobre situações ou } \\
\text { atividades especificas; } \\
\text { - Mensuração de } \\
\text { resultados por meio da } \\
\text { definição de métricas; } \\
\text { - Avaliação dos } \\
\text { investimentos em gestão } \\
\text { do conhecimento. }\end{array}$ & $\begin{array}{l}\text { Terra (2005); } \\
\text { Wong (2005); } \\
\text { Hasanali (2002); } \\
\text { Holsapple and } \\
\text { Joshi (2000). }\end{array}$ \\
\hline
\end{tabular}

FONTE: Elaborado pelo autor

A partir de tal quadro, foi possível fazer algumas constatações. Entre elas, o fato de que a liderança pode ser considerada o fator crítico de sucesso mais citado entre os autores pesquisados, uma vez que $100 \%$ destes a destacam como um FCS da GC, porque o líder influencia os colaboradores a terem o comportamento desejado para a gestão do conhecimento 
e impulsionam a liberdade de interação. Por este motivo, é relevante destacar que o:

líder deve atuar como professor, mentor, guia ou facilitador, incentivando as pessoas e a organização [...] a desenvolverem habilidades fundamentais para a existência de um aprendizado capaz de recriar o mundo (TERRA, 2005, p. 112).

A tecnologia da informação foi citada como FCS da GC por $87,5 \%$ dos autores pesquisados e, para estes, esta se destaca em virtude de ser um dos principais elementos para a implantação da GC e uma ferramenta que viabiliza o registro, o armazenamento, a disseminação e o acesso à informação e ao conhecimento por todos os setores da organização. Tanto Terra (2005) quanto Wong (2005) apontam que não se pode negar que a TI é um dos principais facilitadores na implantação da GC. Terra (2005, p. 191) afirma que os sistemas de informação "tendem a elevar o poder de encontrar conhecimento onde antes havia apenas uma grande quantidade de dados e informação". Wong (2005, p. 269), por sua vez, explica que "sua capacidade evoluiu de ser apenas um arquivo estático de informações para ser um conector de um humano para informação e de um humano para outro."

A cultura organizacional foi destacada para $87,5 \%$ dos autores analisados, por ter a capacidade de direcionar o comportamento dos indivíduos na empresa, valorizando o conhecimento, encorajando sua criação, partilha e uso. Wong (2005, p. 267, tradução nossa) explana que, de modo geral, "uma cultura que apoia a GC é aquela que valoriza o conhecimento e incentiva sua criação, compartilhamento e aplicação." O autor diz ainda que a cultura organizacional "define as principais crenças, valores, normas e costumes sociais que governam o modo como os indivíduos agem e se comportam na organização." (Ibidem). Terra (2005, p. 120) é capaz de complementar tal raciocínio ao dizer que:

tais normas e valores podem ser vistos ainda como sistemas de controle capazes de atingir grande eficácia, uma vez que levam a um alto grau de conformação, ao mesmo tempo que conferem elevada sensação de autonomia.

O fator infraestrutura organizacional é apontado por $75 \%$ dos autores utilizados neste estudo, por tratar da forma como as empresas são estruturadas. Goh (2002) ressalta sua importância ao afirmar que uma infraestrutura apropriada é fundamental ao apoio e reforço na transferência de conhecimento. 
A mensuração de resultados é dita como um fator crítico de sucesso da GC por metade (50\%) dos autores pesquisados. Através desta averiguação é possível analisar se os investimentos na GC estão compensando. Wong (2005, p. 270) diz que a "medição permite que as organizações acompanhem o progresso da GC e determine seus benefícios e eficácia".

Em porcentagens menores, mas não menos importantes, fatores como: treinamento, recursos, aprendizado com o ambiente externo, processos e estratégias são abordados pelos autores utilizados neste estudo. O treinamento foi considerado um FCS da GC, porque é essencial para que haja uma maior e mais rápida adesão dos funcionários à gestão do conhecimento.

Os recursos (financeiros, humanos, materiais), principalmente os humanos, por sua vez, por serem o combustível para a geração do conhecimento, são abordados por alguns autores enquanto determinantes para a implantação da GC. Além disso, o aprendizado com o ambiente externo (em que consumidores, fornecedores e parceiros são capazes de trazer referentes à satisfação dos clientes) pode gerar informações convertidas, posteriormente, em conhecimento. Assim, os processos (processos sistematizados, orientação por processos) podem ser feitos com este conhecimento, entre eles a criação, identificação, o acúmulo, a transferência, e utilização do conhecimento. As estratégias que, quando bem definas, conduzem a GC ao sucesso.

Ademais, as organizações possuem missão, visão e valores específicos, e vão de micro e pequenas empresas até multinacionais. Por este motivo, é necessário adequar e descobrir quais são os FCS mais relevantes para a empresa em específico. A conquista do sucesso na implantação da GC não é um manual de uso, visto que os exemplos, inúmeras vezes são eficientes, porém, cada organização possui suas particularidades, que devem ser consideradas para uma implantação de GC de sucesso.

\section{CONSIDERAÇÕES FINAIS}

Os fatores críticos de sucesso são um conjunto de elementos capazes de influenciar nos resultados positivos das organizações que implantam a Gestão do Conhecimento. Com base nos FCS identificados nesta pesquisa, é possível perceber que alguns estudos levam em consideração apenas fatores internos, enquanto outros se preocupam também com os externos. 
Observou-se que, apesar das pessoas não serem listadas como um FCS, para o bom desempenho destes fatores é necessário o interesse e habilidades pessoais; ou seja, ter os sujeitos ideais é primordial para o crescimento organizacional.

A gestão do conhecimento é um tema muito abrangente. Neste estudo, ele ligou-se a um outro tema, os fatores críticos de sucesso, de modo a formar uma linha de pesquisa mais específica. $O$ estudo realizou uma abordagem geral, sem focar em apenas um tipo de organização, podendo, assim, servir como parâmetro para os diversos tipos de organização que vem emergindo.

Vale ressaltar que existem ferramentas tecnológicas de gestão do conhecimento, e que as empresas ao redor do mundo as têm utilizado cada vez com mais frequência. Algumas destas ferramentas são: Confluence, Bitrix24, AnswerHub, e HEFLO. Sendo assim, abre-se um leque de opções de estudo sobre essas ferramentas, como funcionam e em que grau podem auxiliar GC. Outro tema pensável de ser estudado são os níveis de maturidade na gestão do conhecimento.

A grande dificuldade encontrada na elaboração do presente estudo deu-se pelo fato de que os autores acabam incorporando um elemento a outro. Pode-se citar como exemplo Davenport et al (1998), que reúne a infraestrutura técnica e a organizacional em um único princípio; ou, então, utilizam termos diferentes para designar fatores com a mesma característica. Outro impasse foi que alguns autores falam de maneira indireta, não deixando claro o fator, e acabam listando um fator dentro de outro, sem colocá-lo de forma separada.

\section{REFERENCIAS}

ARORA, R. Implementing KM - a balanced score card approach. Journal of Knowledge Management, v. 6, n. 3, p. 240-249, 2002.

BARROS, J. da S. et al. Gestão do conhecimento: ações e ferramentas para a superação de barreiras no compartilhamento do conhecimento. Ponto de Acesso, v. 4, n. 2, p. 33-57, 2010

BIBLIOTECA Dante Moreira Leite - 0 que é revisão da literatura?. SÃO PAULO, [2013?]. 1 folder. Disponível em: <http://www.ip.usp.br/site/wpcontent/uploads/2016/09/Folheto_RevisaoLiteratura_2014.pdf> Acesso em: 15 de janeiro de 2019

BRASCHER, M; CAFÉ, L. Organização da informação ou organização do conhecimento? In: ENCONTRO NACIONAL DE PESQUISA EM PÓS-GRADUAÇÃO EM CIÊNCIA DA INFORMAÇÃO, 9. 2008, São Paulo. Anais... São Paulo: USP, 2008. p. 1-14 
BRITO, L. M. P. Gestão do conhecimento — instrumento de apropriação pelo capital do saber do trabalhador. Cadernos de Educação, n. 30, p. 135-148, jan./jun. 2008. Disponível em: <https://periodicos.ufpel.edu.br/ ojs2/index.php/caduc/article/viewFile/1767/1642> Acesso em: 15 de janeiro de 2019

CHOO, C. W. A organização do conhecimento. São Paulo: Senac, 2003. 426p.

DAMODARAN, L.; OLPHERT, W. Barriers and facilitators to the use of Knowledge management systems, Behavior and Information Technology, v. 19, n. 6, p. 405-413, 2000.

DAVENPORT, T.; PRUSAK, L. Conhecimento empresarial: como as organizações gerenciam o seu capital intelectual. Rio de Janeiro: Campus, 1998. 256p.

DAVENPORT, T.H., De LONG, D.W. and BEERS, M.C. "Successful knowledge management projects", Sloan Management Review, v. 39, n. 2, p. 43-57, 1998.

DRUCKER, P. Desafios gerenciais para o século XXI. São Paulo: Pioneira, 1999.

FLORIANO, P. R. Sete obstáculos ao compartilhamento do conhecimento e três maneiras de superá-los. Terra Fórum Consultores. [200?] p. 1-8 Disponível em: <https://pt.slideshare.net/pfloriano/seteobstaculos-ao-compartilhamento-do-con> Acesso em: 15 de janeiro de 2019 GALVÃO, M. C. B. O levantamento bibliográfico e a pesquisa cientifica. In: FRANCO, L. J.; PASSOS, A. D. C. (Org.). Fundamentos da epidemiologia. 2. ed. São Paulo: Manole, 2010. p. 377-398.

$\mathrm{GOH}, \mathrm{S}$. Managing effective knowledge transfer: an integrative framework and some practice implications. Journal of Knowledge Management, v. 6, n. 1, p. 23-30, 2002.

GONÇALVES, C. M.; COLAUTO, R. D.; BEUREN, I. M. Identificação dos Fatores Críticos de Sucesso em Instituição de Ensino Superior. In: COLÓQUIO INTERNACIONAL SOBRE GESTÃO UNIVERSITÁRIA NA AMÉRICA DO SUL, 4, 2004, Florianópolis. Anais... Florianópolis: UFSC, 2010. p. 1-15.

HASANALI, F. Critical success factors of knowledge management. Knowledge Management Advantage, 2002. Disponível em: $<$ http://providersedge.com/docs/km_articles/Critical_Success_Factors_of_K M.pdf>. Acesso em: 15 de janeiro de 2019

HOFFMANN, W. A. M. (Org.) Construções interdisciplinares em gestão do conhecimento. São Carlos: Pedro \& João Editores, 2016. 239p.

HOLSAPPLE, C.W.; JOSHI, K.D. An investigation of factors that influence the management of knowledge in organizations. Journal of Strategic Information Systems, v. 9, n. 2/3, p. 235-261, 2000. 
JARRAR, Y. F. Knowledge management: learning for organisational experience. Managerial Auditing Journal, v. 17, n. 6, p. 322-328, 2002.

JENNEX, M.; OLFMAN. L. Assessing Knowledge Management Success/Effectiveness Models. In: HAWAll INTERNATIONAL CONFERENCE ON SYSTEM SCIENCES, 37., 2004, Big Island. Proceedings... Big Island: IEEE, 2004. p. 1-10. Disponível em: $<$ https://ieeexplore.ieee.org/stamp/stamp.jsp?arnumber=1265571>. Acesso em: 15 de janeiro de 2019

NONAKA, I.; TAKEUCHI H. Criação de conhecimento na empresa: como as empresas japonesas geram a dinâmica da inovação. 14. ed. Rio de Janeiro: Elsevier, 1997.

SILVA, S. L. Gestão do conhecimento: uma revisão crítica orientada pela abordagem da criação do conhecimento, Ci. Inf., Brasília, v. 33, n. 2, p. 143-151, maio/ago. 2004.

SKYRME, D. and AMIDON, D. "The knowledge agenda". Journal of Knowledge Management, v. 1, n. 1, p. 27-37, 1997.

SOUZA, E. D. de; DIAS, E. J. W.; NASSIF, M. E. A GESTÃO DA INFORMAÇÃO E DO CONHECIMENTO NA CIÊNCIA DA INFORMAÇÃO: perspectivas Teóricas e Práticas Organizacionais, Inf. \& Soc.: Est., João Pessoa, v. 21, n. 1, p. 55-70, jan./abr. 2011.

TARAPANOFF, Kira. (Org.). Inteligência organizacional e competitiva. Brasília: Editora UNB, 2001. p. 303-326.

TEIXEIRA FILHO, J. Gerenciando conhecimento: como a empresa pode usar a memória organizacional e inteligência competitiva no desenvolvimento de negócios. Rio de Janeiro: SENAC, 2000.

TERRA, J. C. C. Gestão do Conhecimento: o grande desafio empresarial. 5. ed. Rio de Janeiro: Elsevier, 2005.

VALENTIM, M. L. P. Gestão da informação e gestão do conhecimento: especificidades e convergências. INFOHome. 2004. Disponível em: $<$ http://www.ofaj.com.br/colunas_conteudo.php?cod=88>. Acesso em: $15 \mathrm{de}$ janeiro de 2019

WILSON, T. D. A problemática da gestão do conhecimento. In: TARAPANOFF, K. Inteligência, informação e conhecimento em corporações. Brasília: IBICT; UNESCO, 2006. p. 37-55.

WONG, K.Y. "Critical success factors for implementing knowledge management in small and medium enterprises", Industrial Management \& Data Systems, v. 105, n. 3, p. 261-279, 2005.

Recebido em: 16/01/2019

Aceito em: 05/06/2019 